\title{
COLLECTIVE EMOTIONAL ATMOSPHERE IN MATHEMATICS LESSON BASED ON FINNISH FIFTH GRADERS? DRAWINGS
}

\author{
Anu Laine, Maija Ahtee, Liisa Näveri, Erkki Pehkonen, Päivi Portaankorva-Koivisto \& \\ Laura Tuohilampi \\ University of Helsinki • anu.laine@ helsinki.fi
}

\begin{abstract}
The aim of this study, based on pupils' drawings, is to find out what kind of collective emotional atmosphere dominates in fifth-graders' mathematics lessons. Pupils' $(\mathrm{N}=136)$ drawings were analyzed using a holistic evaluation of emotional atmosphere during mathematics lesson. Even though the collective emotional atmosphere in mathematics lesson is positive in the total data, there are large differences among the different classrooms. In most of the classrooms the emotional atmosphere could be described more or less as ambivalent (there are both positive and negative facial or other expressions). In two classrooms the emotional atmosphere could be described as positive and only in one as neutral. The differences between the classrooms are thus large. Based on our data, it can be said that asking pupils to do drawings is a good and many-sided method to collect data about the collective emotional atmosphere of a teaching group.
\end{abstract}

\section{Introduction}

In international studies such as TIMSS 2011 and Pisa 2009, Finnish pupils' learning achievements in mathematics have been very good, up to excellent (Mullis et al. 2012, OECD 2010). These pupils' attitudes, beliefs and motivation, however, are not the best possible. For example, in TIMSS 2011 study one third (compared to the international mean of $48 \%$ ) of Finnish $4^{\text {th }}$ graders' and one tenth of $8^{\text {th }}$ graders' (mean 26\%) attitudes toward mathematics were positive. Pupils' self-beliefs were on a par with the international average although Finnish students' knowledge was among the best. Finnish pupils' commitment to their studies was weak. Only one fifth (vs. $42 \%$ ) of $4^{\text {th }}$ graders and $6 \%$ (vs. $25 \%$ ) of $8^{\text {th }}$ graders were committed to studying mathematics (Mullis et al. 2012). Based on a new national longitudinal study, Finnish pupils' attitudes toward mathematics, as well as their self-beliefs and especially self-efficacy beliefs, deteriorate year by year from the third to the ninth grade (Tuohilampi \& Hannula 2013).

The Finnish National Board of Education assessed learning outcomes in mathematics among pupils who had finished the $5^{\text {th }}$ grade of basic education in September 2008 (Niemi 2010). Data was collected through stratified sampling from 288 comprehensive schools. The sample covered 5,560 pupils, consisting of 2,844 boys and 2,716 girls. On average, pupils performed well in the mathematics test. On the whole there were no major differences in pupils' learning outcomes. However, there were considerable differences between individual schools. In this connection, the fifth graders answered also on a questionnaire in which they were asked in five-level Likert-scale how they enjoyed their stay at school, and about their attitudes toward mathematics. The majority of the pupils 
enjoyed themselves either fairly or very well at school. Pupils' enjoyment had, however, a clear connection to their success in the mathematics test. There was also a clear connection between the fifth graders' attitudes and their success in the mathematics test. The more positive a pupil's attitude was, the better s/he succeeded in the test. On the whole the girls' attitudes toward mathematics were more negative than the boys' attitudes.

The Finnish National Core Curriculum for Basic Education (NBE 2004) emphasizes the importance to create a learning environment having an open, encouraging, easygoing, and positive atmosphere, and that the responsibility to maintain this belongs to both the teacher and the pupils. The aim of teaching mathematics is to offer opportunities to develop pupils' knowledge and skills in mathematics, and in addition to guide pupils towards goal-directed activities and social interaction.

Teachers have a central role in advancing the affective atmosphere and social interaction in their class. Harrison, Clarke and Ungerer (2007) summarize that a positive teacher-pupil relation advances both pupils' social accommodation and their orientation to school, and it is thus an important foundation for the pupils' academic career in future. Positive friendships seem also to increase pupils' active school attendance. A pupil's advancement in school is connected to the factors that have an effect on social relations in the class like controlling emotions, liking school, eligibility as a mate, adjustment to school environment and self-control. In several studies, it has clearly been found, that there is a close connection between the atmosphere in the classroom and learning achievements as well as emotional and social experiences (e.g. Frenzel, Pekrun \& Goetz 2007; Evans, Harvey, Buckley \& Yan 2009).

The purpose of this study is to find out what kind of emotional atmosphere dominates in fifth graders' mathematics lessons. For this purpose, we will use pupils' drawings as research data.

\subsection{Dimensions to the collective emotional atmosphere in a classroom}

Evans et al. (2009) define three complementing components of classroom atmosphere: 1) academic, referring to pedagogical and curricular elements of the learning environment, 2) management, referring to discipline styles for maintaining order, and 3) emotional, referring to the affective interactions within the classroom. In this study, we concentrate on the last component i.e. emotional atmosphere, which can be noticed for example as an emotional relation between the pupils and the teacher.

The emotional atmosphere within the classroom can be regarded either from the viewpoint of individuals in the class (psychological dimension) or from the viewpoint of a community (social dimension). While the individual perspective looks at the individual experiences in the class, the social perspective looks at the class more holistically with a focus on social interaction, communication and norms. Furthermore, a distinction can be made between two temporal aspects of affect: state and trait. State refers to the emotional 
atmosphere in a specific moment in the class while trait refers to more stable condition or property. These form a matrix shown in Table 1. (Hannula 2011.)

Table 1 Dimensions to the emotional atmosphere in a classroom (see Hannula 2011)

\begin{tabular}{lll}
\hline & $\begin{array}{l}\text { Psychological dimension or the } \\
\text { level of an individual }\end{array}$ & $\begin{array}{l}\text { Social dimension or the level of a } \\
\text { community (classroom) }\end{array}$ \\
\hline $\begin{array}{l}\text { Affective condition } \\
\text { (state) }\end{array}$ & $\begin{array}{l}\text { Emotions and emotional reactions } \\
\text { Thoughts }\end{array}$ & $\begin{array}{l}\text { Social interaction } \\
\text { Communication }\end{array}$ \\
& Meanings & $\begin{array}{l}\text { Atmosphere in a classroom } \\
\text { (momentarily) }\end{array}$ \\
& Goals & \\
Affective property & Attitudes \\
& Beliefs & Norms \\
& Values & Social structures \\
& Motivational orientations & Atmosphere in a classroom \\
& &
\end{tabular}

At an individual's level the rapidly appearing and disappearing affective states are different emotions and emotional reactions (e.g., fear and joy), thoughts (e.g., "This task is difficult."), meanings (e.g., "I could do it."), and aims (e.g., I want to finish this task."). From this perspective, the state emotional atmosphere is the collection of such individual affective states in the class at any moment. On the other hand, more stable affective traits are related to attitudes (e.g., "I like mathematics."), beliefs (e.g., "Mathematics is difficult."), values (e.g., "Mathematics is important."), and motivational orientations (e.g.. "I want to understand."). The trait emotional atmosphere is the collection of such individual affective states in the class.

Different affective dimensions can be studied also using social level concepts at the level of community i.e. of a classroom. Rapidly changing affective states include, for instance, a social interaction connected to a certain situation, communication related to this, and the emotional atmosphere present in the classroom. As an example one can think about the situation when the homework is being checked in the beginning of a mathematics lesson. This situation can differ quit a lot in different classrooms. In one classroom pupils are working in pairs and the atmosphere - as seen through the emotional tone of communication - is jovial. In another classroom the teacher is walking around and s/he criticizes the pupils who have not done their homework. S/he also appoints certain pupils to present their solutions on the blackboard. The emotional tone of the social interaction, or the atmosphere, for this classroom is one of control and criticism. 
When similar situations happen repeatedly in a classroom, students may form more stable affective traits typical to a certain classroom. Social norms (cf. Cobb \& Yackel 1996), social structures and atmosphere in a classroom are such traits. Pupils will "learn" that during mathematics lessons homework is always checked in the same way, and a certain norm is developed. When also other parts of the mathematics lesson happen repeatedly in the same kind of atmosphere, the atmosphere may become general and include all mathematics lessons, possibly also lessons of other subjects.

The collective concepts are not just a collection of the beliefs and conceptions of individuals (Cobb and Yackel 1996). The collective concepts, like norms, are formed in joint action (Blumer 1969, see also Partanen 2011). One pupils' interpretation about emotional states of the others and herself in a classroom also shows somehow her interpretation of the collective experience in the classroom. If these interpretations of all pupils in the classroom are put together that could be a feature of the joint action and in the long run, the collective emotional atmosphere of the classroom.

\subsection{Pupils' drawings as a research object}

Drawing is an alternative form of expression for children. For example, Barlow, Jolley and Hallam (2011) have noted that free hand drawings help children recall and express more details about events they depicted. Drawings tend to facilitate the recalling of events that are unique, interesting or emotional, but not routine events or isolated bits of information that are not part of a narrative. Furthermore, we want to emphasize that pupils' drawings open a holistic way to evaluate and monitor the classroom climate.

Many researchers (e.g. Aronsson \& Andersson 1996; Murphy, Delli \& Edwards 2004) have used pupils' classroom drawings, and realized that they form rich data to reach children's conceptions on teaching. Drawings can be used, for example, to find out latent emotional experiences (Kearney \& Hyle 2004). Harrison et al. (2007) point out that the expression of emotions, particularly negative or difficult emotions, may be managed more easily through drawing than by directly voicing these feelings. Also researchers in mathematics teaching (e.g. Tikkanen 2008; Dahlgren \& Sumpter 2010) emphasize that one way to evaluate teaching are pupils' drawings about mathematics lesson. The drawings tell also about beliefs, attitudes and emotions related to mathematics.

According to Picard and Gauthier (2012), expressive drawings represent drawers' emotions literally, metaphorically and abstractly. Young, 5-10 year-old children usually represent emotions only literally by facial expressions whereas 11-15 year-old children use also metaphorical expressions. Children use different types of expressive drawing techniques while drawing different topics. For example, expressive drawings about people mostly call for literal expression, whereas drawings of nonhuman topics (house, tree) preferentially trigger more complex expressive techniques, either including or restricted to metaphorical expression. Also different emotions are drawn by using different techniques: 
in contrast to happiness, sadness elicit metaphorical expression more often than literal expression. (Picard \& Gauthier 2012.)

\subsection{The purpose of the study}

This article is linked to the comparative study between Finland and Chile 2010-2013, a research project (project \#135556) which was partly funded by the Academy of Finland. The purpose of the project is to study the development of pupils' mathematical understanding and problem-solving skills from the third grade to the fifth grade when open tasks are used in teaching at least once a month. The data in this article consist of drawings that were collected in the spring of 2013 as part of the project's initial measurements. In the earlier article we have looked at what kind of emotional atmosphere is found in third-graders' drawings (Laine, Näveri, Ahtee, Hannula, \& Pehkonen, 2013). We have also studied what kind of teaching methods and communication (Tikkanen, Ahtee, Pehkonen, Laine, Heinilä, \& Näveri, 2011), and mathematics (Näveri, Laine, Ahtee, Pehkonen, \& Tikkanen, 2014) can be found in the pupils' drawings in Finland.

In this article, the meanings the drawer gives to the events in a mathematics lesson are regarded in the social context of the lesson. First, we are interested in each pupil's individual perception of their class and, secondly, we are interested in the collection of the individual perceptions in each classroom. Each picture shows the drawer's interpretations of the emotional states of the others and her/himself in the classroom, but it also shows drawer's interpretation of the collective experience in the classroom.

The research problem is thus: "What kind of emotional atmosphere in a mathematics lesson can be seen in fifth-graders' drawings?” The holistic emotional atmosphere of a teaching group describes the situation as a whole that can be concluded from the facial expressions and communication in the drawing. Here two levels of the emotional atmosphere during a mathematics lesson can be distinguished: a general emotional atmosphere as described by all the pupils in this study, and the emotional atmosphere of a certain classroom.

The research questions are as follows:

1. What kind of collective emotional atmosphere in a mathematics lesson can be seen in fifth-graders' drawings?

2. How does the collective emotional atmosphere differ between different teaching groups?

\section{Method}

\subsection{Participants and data collection}

The fifth-graders (about 11-12 years old) came from eight classes taught by different teachers in five primary schools in the Helsinki metropolitan area. The pupils drew a mathematics lesson scenario as their task in the end of the 2013 spring term. All the pupils who were at school at that day did the drawing (about $85 \%$ of the pupils). 
The task given to the pupils was:

"Draw your teaching group, the teacher and the pupils in a mathematics lesson. Use speech bubbles and thought bubbles to describe conversation and thinking. Mark the pupil that represents you in the drawing by writing ME."

In total 136 pupils' drawings were analyzed, out of which 73 were drawn by boys and 58 by girls. There were also 5 drawings without identification. The words in the speech and thought bubbles enabled the study of communication between the teacher and pupils.

\subsection{Data analysis}

A drawing as an observational data can be divided into content categories (Tikkanen 2008). A content category means a phenomenon on which data are gathered. A content category is further specified into subcategories. In this article, we are concentrating only on the holistic evaluation of the emotional atmosphere in a classroom which is based on all the pupils' and the teacher's moods seen in a drawing as well as on the pupils' speech and thought bubbles in the picture. The pupils' and the teacher's mood is determined on the form of the mouth (smiling, neutral, sad/angry, not visible). The nature of the speech and thought bubbles is classified into three subcategories: positive (e.g. "Mathematics is fun."), negative (e.g. "Mathematics is hard.") and neutral (e.g. "Four times four is sixteen."). The holistic evaluation of the emotional atmosphere in a classroom is thus based on five categories:

1) positive (persons smile and/or think positively, some can be neutral);

2) positive and negative (ambivalent), there are both positive and negative facial or other expressions found in the drawing;

3) negative (persons are sad or angry or think negatively, some can be neutral);

4) neutral, (all facial or other expressions are neutral).

5) unidentifiable (when it is impossible to see any facial or other expressions)

In order to get an overview of the emotional atmosphere of the whole teaching group we made a summary of the holistic evaluation of the individual pupils' drawings. In addition to analyzing individual pupils' views of the emotional atmosphere in their classroom we wanted to see how these individual views varied in different classrooms. It is important to notice that we were interested in the general atmosphere during mathematics lessons and not specific feelings toward mathematics activities.

Pupils' drawings varied a lot especially from the analyzing point of view. In some drawings persons were presented as stick figures, whereas some of the fifth-graders were very talented illustrators, and then the drawings contained many details. All in all, many drawings seem to be dashed quite quickly. Some of them contained marks of beginning puberty and rebellion against the school. They also contained some features that could be interpreted as metaphorical representation (see Picard \& Gauthier 2012). An example is presented in figure 1. The boy on left is farting and wearing a baseball cap. He is also having some kind of drinking can in his hand. The boy in the middle is saying LOL (laugh out 


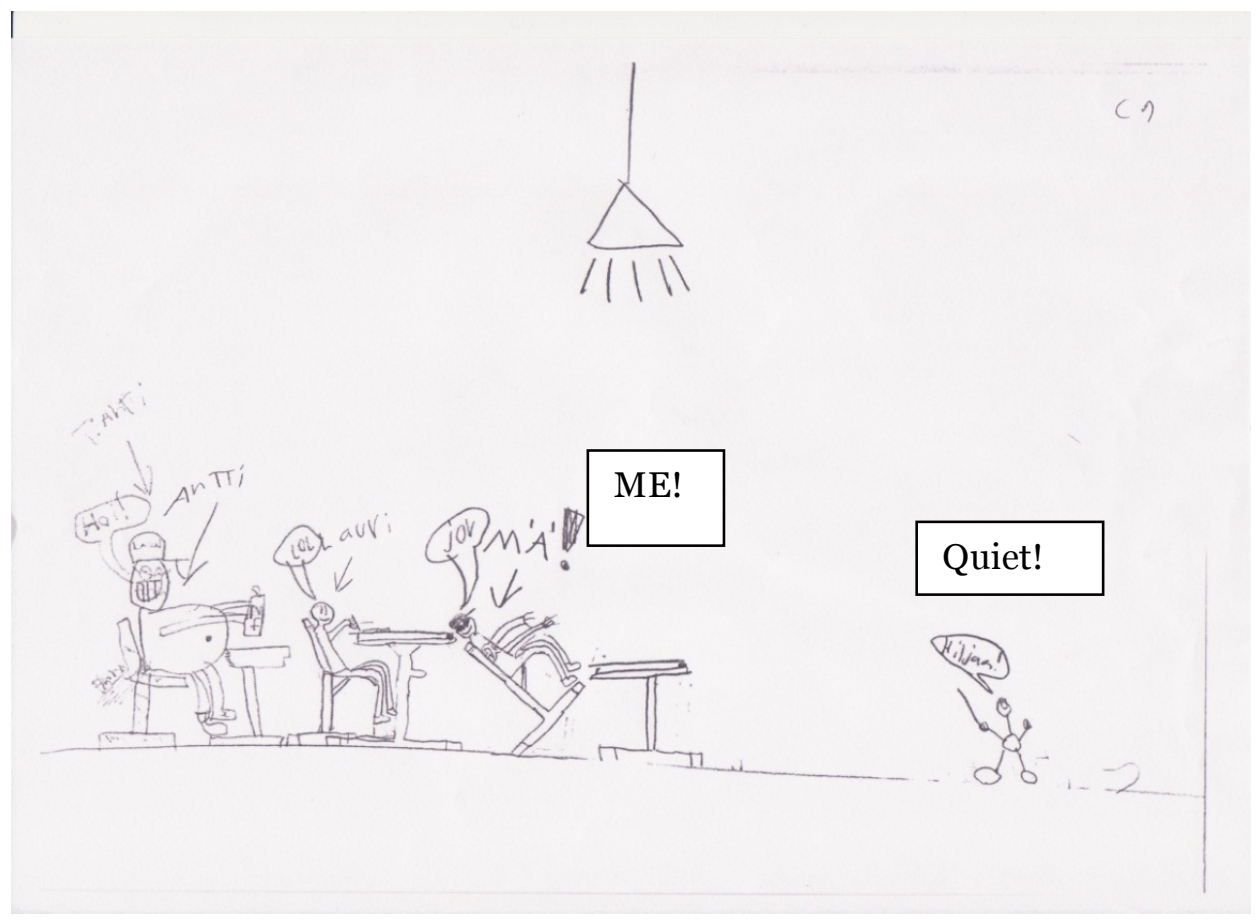

Figure 1 Example of rebellion and metaphorical expressions

loud). The drawer, ME, is swaying on the chair and saying JOU. In addition he is wearing a baseball cap and sunglasses. The teacher in the right is drawn very small and $\mathrm{s} / \mathrm{he}$ is waving a pointer and shouting: Quiet!

Two researchers classified the pupils' drawings together so that they both formed first their own opinion and then the opinions were discussed. Their agreement of the classifications was almost $100 \%$ because they had done similar classifications already earlier. Difficulties in classification were mostly due to pupils' obscure drawings. The analysis of the drawings was qualitative, and it can be classified as inductive content analysis (Patton 2002), as we were trying to describe the situation in the drawing without letting our own opinions influence it. The drawings were analysed one content category at a time.

\section{Results}

\subsection{Emotional atmosphere in a mathematics lesson}

The emotional atmosphere in a mathematics lesson is taken as an entirety that consists of the pupils' and the teacher's facial expressions and their utterances or thoughts. It is classified using the scale: positive, ambivalent, negative, neutral, and unidentifiable. The summary of the emotional atmospheres of a mathematics lesson is presented in Table 2.

Table 2 Collective emotional atmosphere in a fifth-grade mathematics lesson

\begin{tabular}{llllll}
\hline & Positive & Ambivalent & Negative & Neutral & Unidentifiable \\
\hline total (136) & $49(36 \%)$ & $46(34 \%)$ & $19(14 \%)$ & $18(13 \%)$ & $4(3 \%)$ \\
\hline
\end{tabular}


The mode of the emotional atmosphere in mathematics lessons is positive ( $36 \%$ of the drawings) and there were no statistical differences between boys' and girls' drawings. A drawing classified as positive is presented in Figure 2. The drawing is positive because the teacher is smiling and both the teacher's and the pupils' speech or thought bubbles are either positive or neutral.

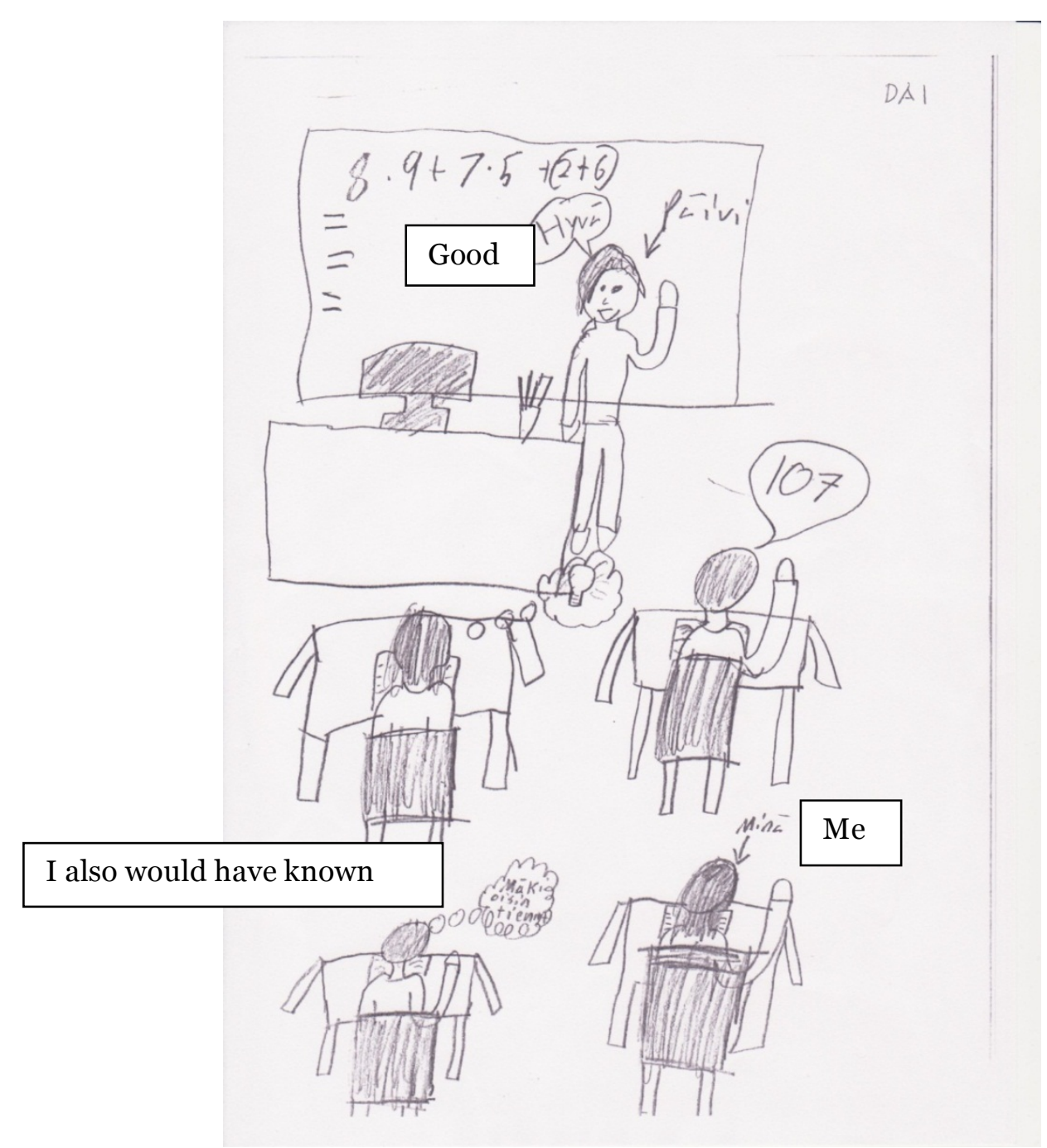

Figure 2 An example of a positive emotional atmosphere

In Figure 2 the teacher is standing in the front of the class and she is giving positive feedback to the pupil who gave the correct answer. The drawer (Me) is raising her hand to show the teacher that she too is willing to answer the question presented at the blackboard. The pupil on the left in the front row has drawn a lamp in the thought bubble to imply the insight. The pupil sitting behind this pupil has also the hand up and s/he is thinking "I also would have known."

The number of the pupils (34\% of the drawings) who portrayed the emotional atmosphere in their mathematics lesson as ambivalent is almost the same as of those pupils who described it as positive. An example of an ambivalent case is presented in Figure 3. 


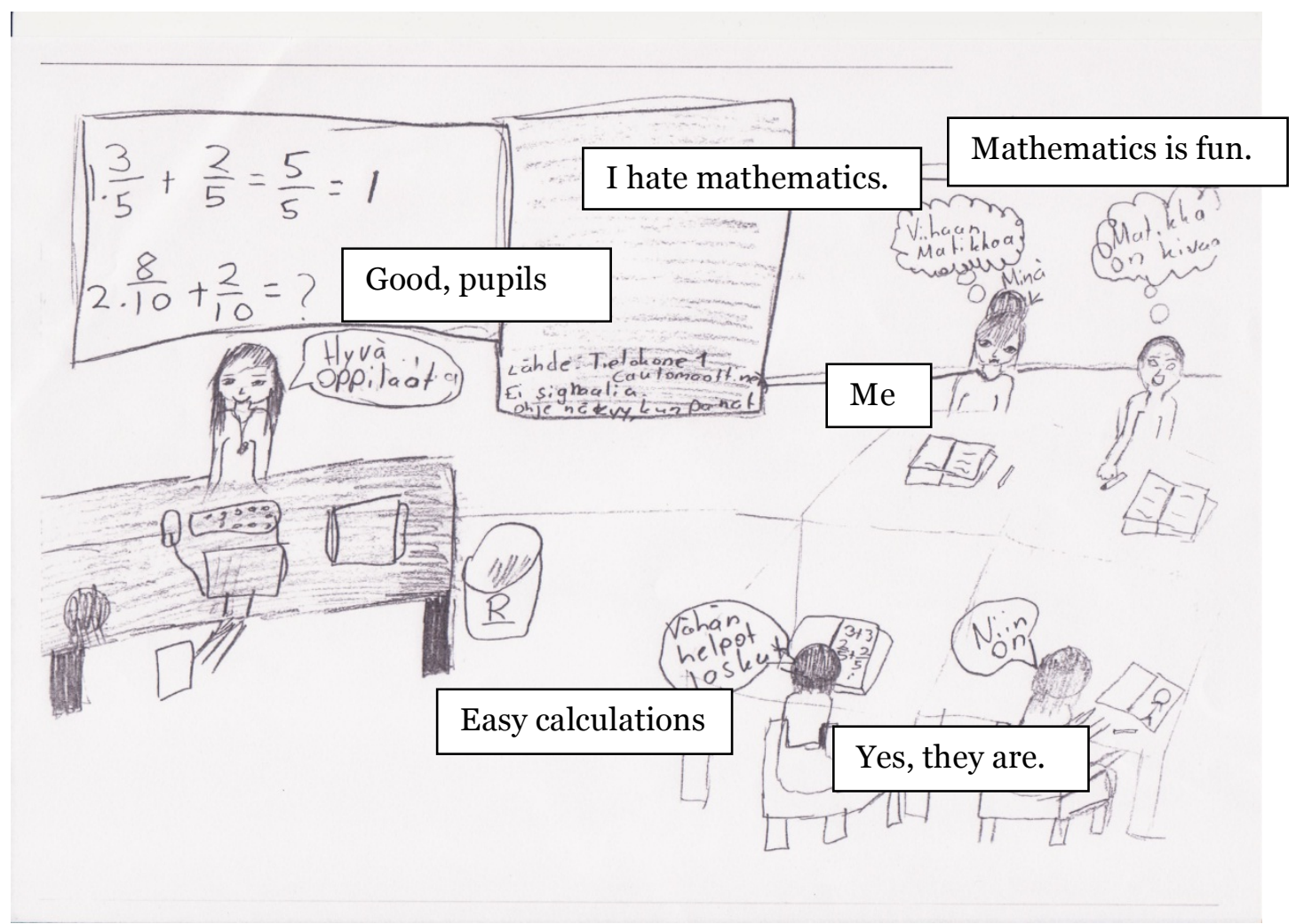

Figure 3 An example of an ambivalent emotional atmosphere

The teacher is sitting behind her desk in the left side of the picture and she is praising the pupils. The drawer (Me) is sitting so that her face is towards the viewer. She is thinking "I hate mathematics", whereas the pupil beside the drawer is thinking the opposite. The two other pupils sitting in the same group are talking with each other stating that the tasks are easy.

In $14 \%$ of the drawings the pupils pictured the emotional atmosphere as negative i.e. they drew sad or angry faces and/or the speech bubbles contained negative (or neutral) thoughts. In Figure 4 there is an example of a drawing showing a very negative emotional atmosphere.

In figure 4, the teacher is in front of the black board. She is showing a quite complicated calculation and saying: "Blaa blaa blaa." The drawer (Me) is sitting in the left. His lips are drawn strongly down and he is thinking about teacher's teaching: "Boring. How can she keep going on?" The pupil next to the drawer is sarcastically commenting the teaching. In the group in the upper right corner one pupil is sleeping, the other is dreaming of a hamburger, and the third one is thinking: "This is absurd." In the group in the lower left corner one of the pupils is swaying on his chair and thinking: "I will die." In another group in the lower right corner one of the pupils is also commenting the teacher's talking: "Don't bother."

In $13 \%$ of the drawings the emotional atmosphere were classified as neutral because the persons' facial or other expressions were neither positive nor negative. Pupils and teachers were normally talking only about mathematical tasks like in Figure 5 . 


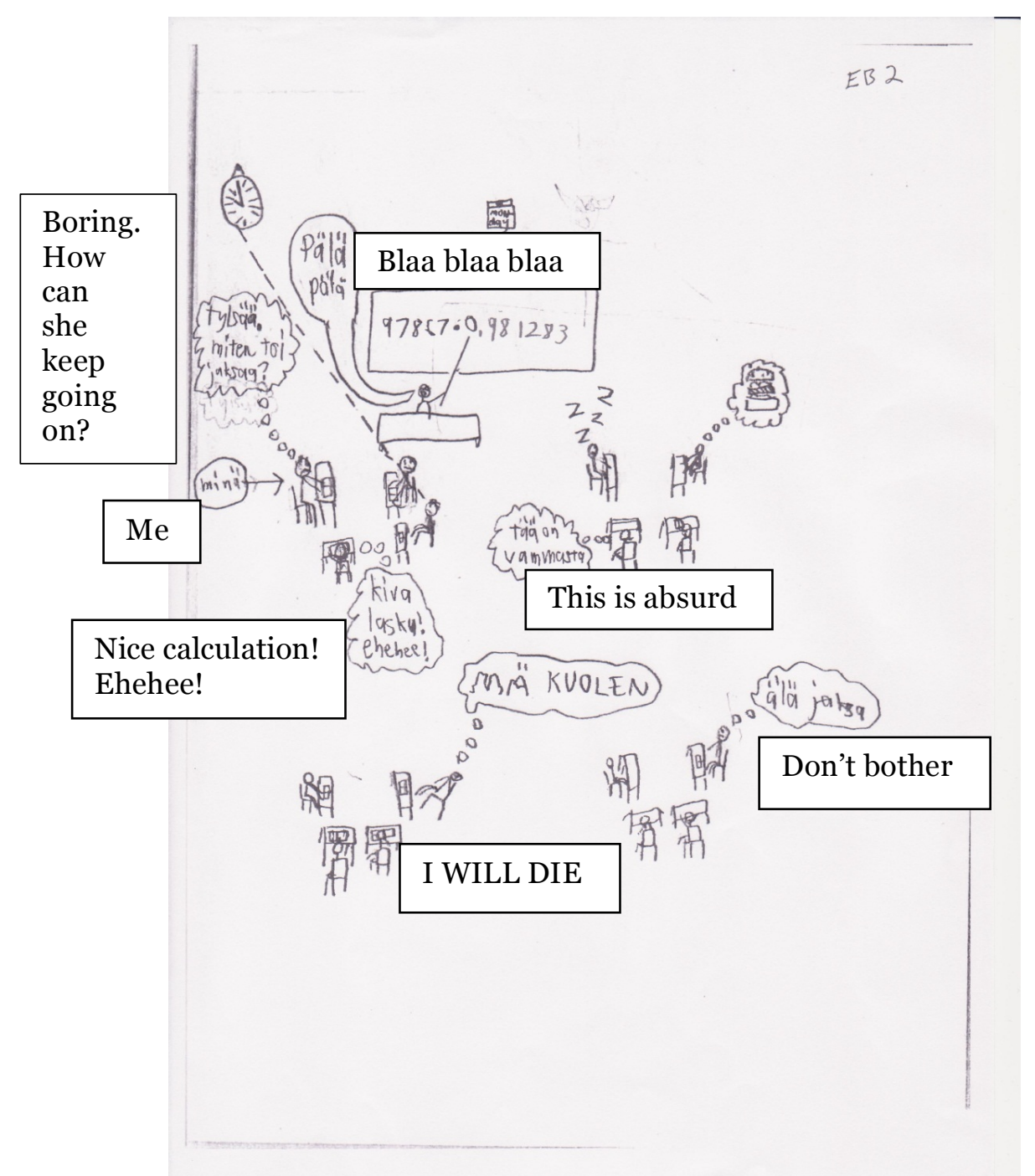

Figure 4 An example of a negative emotional atmosphere

In figure 5, the teacher is standing on the black board and writing instructions to the pupils. The drawer (Me) is doing calculations. Both are illustrated from back so we are not able to see their faces.

The mode of the emotional atmosphere in mathematics lessons is positive (36\% of the drawings), with both the teacher and all the pupils smiling (or some of them neutral) and/or thinking positively/neutrally. On the other hand, only in $14 \%$ of the pictures the emotional atmosphere is negative, so that in the fifth graders' drawings the mood in mathematics lessons is more positive than negative.

\subsection{Collective emotional atmosphere in different classrooms}

Next we are looking at classroom-specific collective emotional atmosphere in mathematics lesson found in the fifth-graders' drawings from the classes of eight different teachers A-H. We made a summary of the holistic evaluation of the individual pupils' drawings in order to 


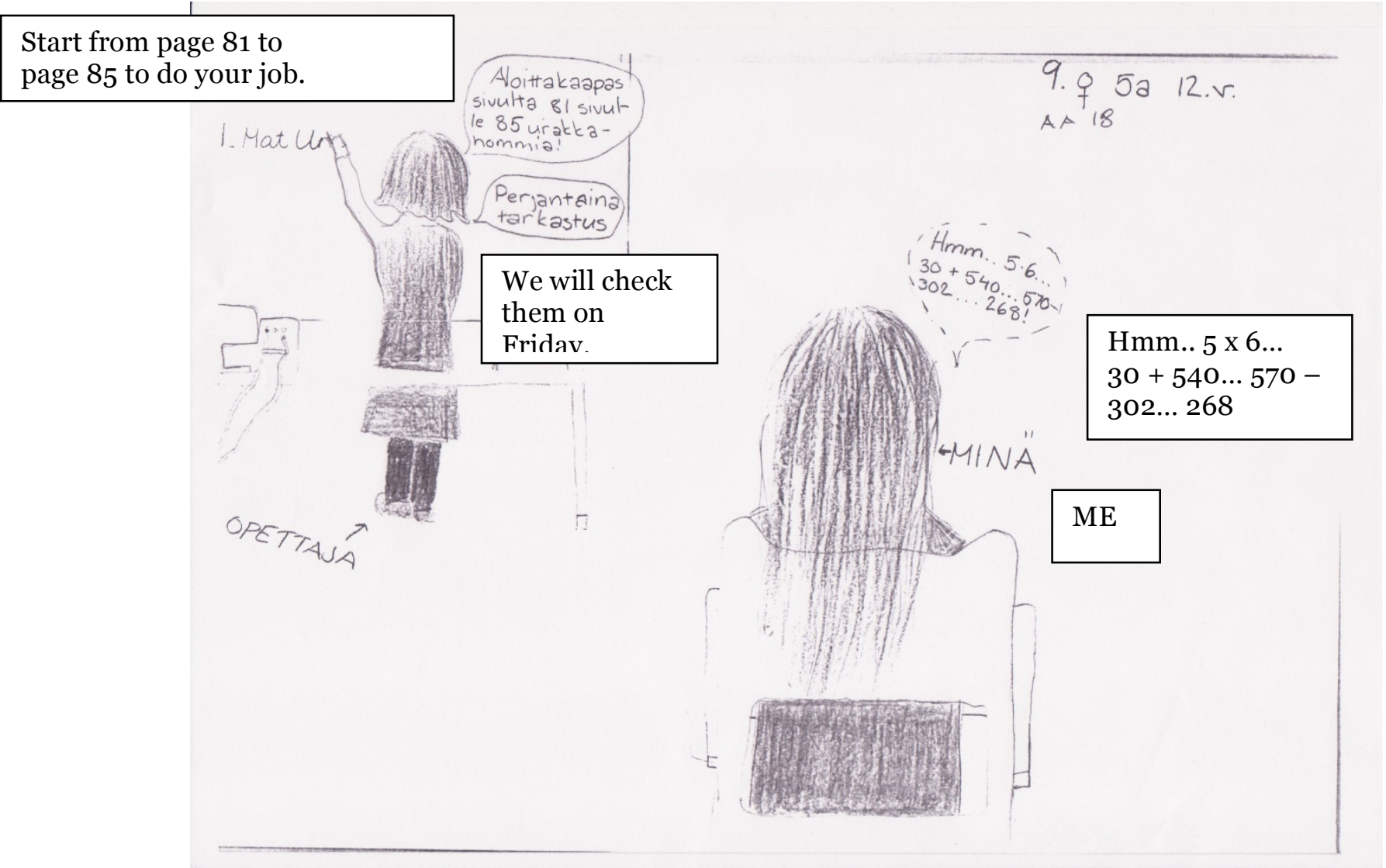

Figure 5 An example of a neutral emotional atmosphere

get an overview of the emotional atmosphere of the whole class. The summary of collective emotional atmosphere in the different classrooms is presented in Table 3.

Even though the collective emotional atmosphere in mathematics lesson is positive in the total data (see Table 2), there are large differences among the different classrooms. In two classrooms ( $\mathrm{C}$ and $\mathrm{F}$ ) the emotional atmosphere of the teaching group could be interpreted as positive because the mode of the emotional atmosphere is positive in these classrooms (see Table 3). The emotional atmosphere illustrated by the pupils is exceptionally positive in classroom C. Almost 60\% of the pupils presented the emotional atmosphere in the classroom as positive and none of them had drawn it negative or neutral; rest of the pupils (42\%) draw an ambivalent picture which containing both positive and negative expressions. The emotional atmosphere in classroom $\mathrm{F}$ is also clearly very positive: $42 \%$ of the pupils draw a positive picture and only $5 \%$ a negative picture. Here one fourth of the drawings were classified as ambivalent. Only in classroom D the mode of the emotional atmosphere is neutral (39\% of the drawings), but also in this classroom there were many positive pictures (33\%) and quite little ambivalent and negative pictures.

In classrooms A, B, E, G and $\mathrm{H}$ the collective emotional atmosphere in the pupils' drawings could be interpreted as ambivalent because in these classrooms pupils had drawn 
Table 3 Distribution of collective emotional atmosphere in mathematics lesson in the eight classrooms

\begin{tabular}{llllll}
\hline & Positive & Ambivalent & Negative & Neutral & Unidentifiable \\
\hline A (18 pupils) & $6(33 \%)$ & $8(44 \%)$ & $3(17 \%)$ & o (0\%) & $1(6 \%)$ \\
B (17 pupils) & $4(24 \%)$ & $5(29 \%)$ & $4(24 \%)$ & $4(24 \%)$ & o (0\%) \\
C (19 pupils) & $11(58 \%)$ & $8(24 \%)$ & $0(0 \%)$ & o (0\%) & o (o\%) \\
D (18 pupils) & $6(33 \%)$ & $2(11 \%)$ & $2(11 \%)$ & $7(39 \%)$ & $1(6 \%)$ \\
E (15 pupils) & $5(33 \%)$ & $5(33 \%)$ & $3(20 \%)$ & $2(13 \%)$ & o (o\%) \\
F (19 pupils) & $8(42 \%)$ & $5(26 \%)$ & $1(5 \%)$ & $4(21 \%)$ & $1(5 \%)$ \\
G (13 pupils) & $3(23 \%)$ & $8(62 \%)$ & $2(15 \%)$ & $0(0 \%)$ & $0(0 \%)$ \\
H (17 pupils) & $6(35 \%)$ & $5(29 \%)$ & $4(24 \%)$ & $1(6 \%)$ & $1(6 \%)$ \\
$\begin{array}{l}\text { average } \\
\text { (136pupils) }\end{array}$ & $49(36 \%)$ & $46(34 \%)$ & $19(14 \%)$ & $18(13 \%)$ & $4(3 \%)$ \\
\hline
\end{tabular}

much both positive and negative pictures. In classroom $\mathrm{G}$, the proportion of ambivalent pictures is very high, over $60 \%$. Furthermore, the number of the positive and negative drawings is close to each other, and none of the pupils describe the atmosphere as neutral. On the other hand, in classroom B 29\% of the drawing are ambivalent. In addition, there are equal amount of positive and negative drawings but $24 \%$ neutral pictures. Whereas in classroom A $44 \%$ of the drawings are ambivalent, and there are twice as many positive than negative pictures but no neutral pictures.

Classroom $\mathrm{H}$ is interesting. There is a big variation in the pupils' drawings: almost the same amount of the pupils' pictures that were interpreted as positive (35\%), ambivalent (29\%) and negative (24\%). Thus the atmosphere in classroom $\mathrm{H}$ must be interpreted as ambivalent. In classroom $\mathrm{E}$ the mode of the emotional atmosphere is both positive (33\%) and ambivalent (33\%). However, fifth of the pupils drew pictures that were analyzed to represent negative emotional atmosphere. That is why this classroom is also interpreted to represent ambivalent emotional atmosphere.

\section{Conclusions}

In the Finnish fifth-graders' drawings the mode value of the collective emotional atmosphere in mathematics lesson is positive although the number of ambivalent pictures was nearly as high. In TIMSS 2011 results one third of fourth graders and only one tenth of eight graders had a positive attitude toward mathematics. In this study, the attitude at the end of fifth grade could be interpreted to be a bit better. Namely only in $14 \%$ of the pupils' drawing the emotional atmosphere was negative. In addition, there were no statistical differences between the emotional atmosphere in boys' and girls' drawings opposite to Niemi (2010) who found that the girls' attitudes toward mathematics were more negative than the boys' attitudes. 
Pictures do not portray straightly pupils' attitudes but it seems possible to obtain more information about this many-sided question by using drawings (see e.g. Kearney \& Hyle 2004).

The most interesting result in this study is the large differences between the collective emotional atmospheres in different classrooms. The Finnish National Core Curriculum for Basic Education (NBE 2004) sets the aim to foster a positive atmosphere in all the classrooms. The teacher has a central role in constructing the emotional atmosphere in mathematics lessons (Evans et al. 2009; Harrison et al. 2007). The teachers' view of mathematics, their stance towards pupils, their pedagogical skills etc. affect the quality of interaction with pupils and thus also the emotional atmosphere. Especially, the emotional relationship between the teacher and the pupils, the teacher's awareness about pupils' feelings and the reasons for these, the teacher's skill to evaluate pupils' feelings and respond to them, the teacher's conception about the importance of different emotions in learning, and the teacher's emotional interpersonal guidelines affect the emotional atmosphere (Evans et al. 2009).

When evaluating a teacher's effect in this study one has to take into account that in some of the classes the teacher had been same from third to fifth grade (classes A, C, D, F and H) whereas in two classes (B and E) the teacher had changed after third grade. This means also that in the classes in which the teacher was not changed the pupils took part in the problem-solving intervention for three year. On the other hand, a pupil's affective conditions and properties affect how they interpret different situations during mathematics lessons (Hannula 2011). It would be interesting to study what the emotional atmosphere is like in the lessons of other subjects. It would be also interesting to compare the situations in third and fifth grade in the same classes.

Based on this research drawings seem to be a versatile way to collect information about the collective emotional atmosphere in mathematics lessons (see also e.g. Harrison et al. 2007). The method offers also a single teacher a possibility to obtain and evaluate information how their pupils experience mathematics and mathematics lessons.

\section{References}

Aronsson, K. \& Andersson, S. (1996). Social scaling in children's drawings of classroom life: A cultural comparative analysis of social scaling in Africa and Sweden. British Journal of Developmental Psychology, 14, 301-314.

Barlow, C. M., Jolley, R. P. \& Hallam, J. L. 2011. Drawings as memory aids: optimising the drawing method to facilitate young children's recall. Applied Cognitive Psychology, 25(3), 480-487.

Blumer, H. (1969). Symbolic interactionism: Perspectives and method. Englewood Cliffs, NJ: Prentice-Hall.

Cobb, P. \& Yackel, E. (1996). Constructivist, Emergent, and Sociocultural Perspectives in the Context of Developmental Research. Educational Psychologist, 31(3/4), 175-190. 
Dahlgren, A. \& Sumpter, L. (2010). Childrens' conceptions about mathematics and mathematics education. In: K. Kislenko (ed.) Proceedings of the MAVI-16 conference June 26-29, 2010, pp. 77-88. Tallinn University of Applied Sciences, Estonia.

Evans, I. M., Harvey, S. T., Bucley, L., \& Yan, E. (2009). Differentiating classroom climate concepts: Academic, management, and emotional environments. New Zealand Journal of Social Sciences, 4(2), 131-146.

Frenzel, A. C., Pekrun, R., \& Goetz, T. (2007). Perceived learning environment and students' emotional experiences: A multilevel analysis of mathematics classrooms. Learning and Instruction, $17(5), 478-493$.

Hannula, M. S. (2011). The structure and dynamics of affect in mathematical thinking and learning. In: M. Pytlak, E. Swoboda, \& T. Rowland (eds.) Proceedings of the seventh Congress of the European Society for Research in Mathematics Education CERME, pp. 34-6o. Poland: University of Rzesów.

Harrison, L. J., Clarke, L., \& Ungerer, J. A. (2007). Children's drawings provide a new perspective on teacher-child relationship quality and school adjustment. Early Childhood Research Quarterly, 22, 55-71.

Kearney, K. S. \& Hyle, A. (2004). Drawing about emotions: the use of participant-produced drawings in qualitative inquiry. Qualitative Research, 4(3), 361-382.

Mullis, I.V.S., Martin, M.O., Foy, P., \& Arora, A. (2012). TIMSS 2011 International Results in Mathematics. Chestnut Hill, MA: TIMSS \& PIRLS International Study Center, Boston College.

NBE 2004. Finnish National Core Curriculum for Basic Education 2004. National Board of Education. http://www.oph.fi/english/publications/2009/national_core_curricula_for_basic_education.

Niemi, E.K. (2010). Matematiikan oppimistulokset 6. luokan alussa. [The learning outcomes in the beginning of the $6^{\text {th }}$ grade.] In E. K. Niemi \& J. Metsämuuronen (Eds.) Miten matematiikan taidot kehittyvät? Matematiikan oppimistulokset peruskoulun viidennen vuosiluokan jälkeen. [How mathematics competences develop? Mathematics learning outcomes after grade 5 in comprehensive school.] Helsinki: Edita Prima Oy.

OECD (2010). PISA 2009 Results: What Students Know and Can Do - Student Performance in Reading, Mathematics and Science. Volume I. http://dx.doi.org/10.1787/9789264091450-en Accessed 10th November 2013.

Partanen, A-M. (2011). Challenging the school mathematics culture: An investigative small-group aaproach. Ethnographic teacher research on social and sociomathematical norms. Acta universitatis Lapponiensis 206. Rovaniemi: University of Lapland.

Patton, M. (2002). Qualitative research \& evaluation methods. Thousand Oaks, CA: Sage.

Pehkonen, E., Ahtee, M., Tikkanen, P., \& Laine, A. (2011). Pupils' conceptions on mathematics lessons revealed via their drawings. In B.Rösken \& M. Casper (Eds.) Current State of Research on Mathematical Beliefs XVII. Proceedings of the MAVI-17 Conference, pp. 182-191. University of Bochum.

Picard, D. \& Gauthier, C. (2012) The Development of Expressive Drawing Abilities during Childhood and into Adolescence. Hindawi Publishing Corporation. Child Development Research.Volume 2012, Article ID 925063.

Tikkanen, P. (2008). "Helpompaa ja hauskempaa kuin luulin.” Matematiikka suomalaisten ja unkarilaisten perusopetuksen neljäsluokkalaisten kokemana. ["Easier and more fun than I thought." Mathematics experienced by by fourth-graders in Finnish and Hungarian comprehensive schools.] Jyväskylä Studies in Education, Psychology and Social Research 337. Jyväskylä: Jyväskylä University Printing House. 